\title{
0 princípio da gestão democrática na educação pública e sua efetivação no âmbito do sistema municipal de ensino de Ponta Grossa-PR
}

\author{
The principle of democratic management in public education and its \\ processing at Ponta Grossa-PR municipal system of education \\ El principio de la gestión democrática en la educación pública y su \\ efectivización en el ámbito del sistema municipal de enseñanza de \\ Ponta Grossa-PR
}

\section{SIMONE DE FÁTIMA FLACH KELLY LETÍCIA DA SILVA SAKATA}

\begin{abstract}
Resumo: Este artigo discute a gestão democrática no âmbito do Sistema Municipal de Ensino de Ponta Grossa-PR. Para tanto, ele apresenta algumas discussões a respeito da gestão democrática dos principais marcos legais e normativos brasileiros sobre a temática para, então, analisar sua efetivação no contexto pesquisado, em especial nas decisões do Conselho Municipal de Educação. Este estudo, de abordagem quanti-qualitativa e utilizando como referencial teórico para a pesquisa o materialismo histórico e dialético, conclui que, embora os pressupostos legais estejam explícitos e amplamente discutidos na academia, sua efetivação está marcada por vinculações políticas e culturais, pois a participação é tutelada pelos interesses governamentais e legitima ações dos gestores públicos sem, necessariamente, promover um debate realmente democrático.
\end{abstract}

Palavras-chave: Sistema Municipal de Ensino. Gestão Democrática. Participação.

\begin{abstract}
This article discusses the democratic management at Ponta Grossa's Municipal System of Education (Parana-Brazil). For this purpose, it presents some discussions about the democratic management of the main Brazilian legal and regulatory frameworks on the subject, and then analyze its execution in the researched context, especially in decisions of the City Board of Education. This study of quantitative and qualitative approach, using as theoretical framework the dialectical and historical materialism concludes that, although the legal requirements are explicit and widely discussed in the academy, its execution is marked by political and cultural linkages, as participation is safeguarded by government interests and legitimate actions of public officials without necessarily promoting a truly democratic debate.
\end{abstract}

Keywords: Municipal System of Education; democratic management; participation.

Resumen: Este texto debate la gestión democrática en el ámbito del Sistema Municipal de Enseñanza de Ponta Grossa (Paraná - Brasil). Para tal, se presentan algunas discusiones a respecto de la gestión democrática de los principales 
marcos legales y normativos brasileños sobre la temática para, entonces, analizar su efectivización en el contexto investigado, en especial en las decisiones del Consejo Municipal de Educación. Este estudio de abordaje cuanti-calitativo y utilizando como referencial teórico para la investigación el materialismo histórico y dialéctico concluye que, aunque los criterios jurídicos estén explícitos y ampliamente discutidos en la academia, su efectuación está marcada por vinculaciones políticas y culturales, pues la participación está tutelada por los intereses gubernamentales y legitima acciones de los gestores públicos, sin, necesariamente promover un debate realmente democrático.

Palabras clave: Sistema Municipal de Enseñanza. Gestión Democrática. Participación.

\section{INTRODUÇÃO}

O presente artigo objetiva apresentar análise sobre o processo de efetivação do princípio constitucional de gestão democrática no ensino público, tendo como locus de pesquisa o Sistema Municipal de Ensino de Ponta GrossaPR. Os dados e as reflexões apresentadas fazem parte do Projeto de Pesquisa desenvolvido na Universidade Estadual de Ponta Grossa (UEPG) intitulado Gestão democrática no ensino público: mapeamento das bases normativas e das condições politico-institucionais dos sistemas municipais de ensino no estado do Paraná. Para tanto, apresentamos o entendimento acadêmico sobre gestão democrática, os principais marcos legais e normativos brasileiros sobre a temática para, então, analisar sua efetivação no âmbito do Sistema Municipal de Ensino.

A investigação tem como referencial metodológico o materialismo histórico e dialético, que auxilia na compreensão da questão pesquisada em seu movimento histórico e como reflexo das contradições do capitalismo. Assim, o referencial teórico oferece o suporte necessário para a superação de uma visão distorcida da realidade para entendê-la em sua totalidade, explicitando os interesses de classe presentes nas decisões e nas ações desenvolvidas no âmbito local.

A esse respeito, é conveniente explicitar que o estudo aqui apresentado é resultado de inúmeros fatores, contraditórios e divergentes, os quais se interligam e se interpenetram, caracterizando-se, assim, como uma tentativa de explicitação da realidade investigada. O ponto de partida para o estudo foi a realidade político-educacional municipal, a qual esteve em muitos momentos obscurecida. No entanto, o aprofundamento do conhecimento sobre essa realidade ofereceu a superação do entendimento desse não real e possibilitou a compreensão da totalidade, conforme explicitado por Kosik (1976) quando expõe sobre o mundo da pseudoconcreticidade:

O complexo de fenômenos que povoam o ambiente cotidiano e a atmosfera comum

550 - RBPAE - v. 32, n. 2, p. 549 - 569 mai./ago. 2016 
da vida humana, que, com a sua regularidade, imediatismo e evidência, penetram na consciência dos indivíduos agentes, assumindo um aspecto independente e natural, constitui-se o mundo da psendoconcreticidade. (KOSIK, 1976, p. 16).

Assim, o estudo realizado ofereceu oportunidade de superar a visão parcial vivenciada no processo e chegar à sua totalidade sem, contudo, negar a contribuição das ações para a constituição da realidade atual.

A destruição da pseudoconcreticidade - que o pensamento dialético tem de efetuar, não nega a existência ou a objetividade daqueles fenômenos, mas destrói a sua pretensa independência, demonstrando o seu caráter mediato e apresentando, contra a sua pretensa independência, prova do seu caráter derivado. (Idem, p. 16).

Com o intuito de superar a visão distorcida do real, a pesquisa sobre gestão democrática, para além das definições e analisando-a na realidade das ações, pode oferecer importante subsídio para a compreensão das contradições que permeiam o funcionamento do sistema municipal de ensino. Nesse sentido, pretendemos contribuir para um entendimento mais amplo sobre como os princípios democráticos se efetivam nas ações e nas propostas políticas dentro do Sistema Municipal de Ensino. Assim sendo,

Transferir a autoridade e a responsabilidade pela gestão de um bem público para o grupo diretamente envolvido no trabalho é uma prática democrática e socialmente justa, desde que não se escondam por trás o incentivo e as ações de natureza corporativa, e tampouco a intenção por parte do Estado de se desfazer de suas obrigações para com a população. (CATANI; GUTIERREZ, 1998, p. 63).

Isso significa dizer que a prática democrática consiste em criar condições de autonomia participativa sem perder as obrigações que convêm a cada participante do processo, especialmente o Estado. Essas relações perpassam um olhar do e para o coletivo de forma que as decisões sejam consensuais e atendam ao interesse geral conforme condições causais e objetivas de determinado momento histórico ${ }^{1}$. Nessa perspectiva, assume papel central, a vontade coletiva, como pressuposto da democracia, tendo na participação dos sujeitos a possibilidade de efetivação. Assim, entendemos que a participação se caracteriza como um dos pressupostos primordiais para que se efetue a gestão democrática.

1 A esse respeito, compactuamos com o pensamento de Antonio Gramsci, quando, ao tecer discussão a respeito da concepção de Sorel, afirma que "é preciso também definir a vontade coletiva e a vontade política em geral no sentido moderno, a vontade como consciência operosa da necessidade histórica, como protagonista de um drama histórico real e efetivo" (GRAMSCI, 2007. p. 17). 


\section{PARTICIPAÇÃO E PROCESSO DEMOCRÁTICO NA DISCUSSÃO DO PRINCÍPIO DE GESTÃO DEMOCRÁTICA NA EDUCAÇÃO PÚBLICA}

O entendimento de gestão democrática no contexto brasileiro não é matéria pacífica, visto que a história social brasileira evidencia poucos períodos democráticos na fase republicana. No entanto, principalmente nas últimas décadas do século XX, a vivência da democracia tornou-se mais evidente no contexto político-social. Em meados dos anos de 1980, o fim da ditadura militar contribuiu para que a democracia, gestada no período ditatorial, pudesse emergir e ser evidenciada não apenas nas reivindicações da sociedade, mas nos documentos normativos e legais que foram construídos após esse período. $\mathrm{Na}$ esteira desse pensamento, as últimas décadas do século XX foram promissoras no desenvolvimento da ideia de participação, especialmente no campo da gestão pública. Segundo Nogueira (2005),

\footnotetext{
Refletindo, por um lado, o avanço da democratização e da diferenciação social e, por outro, a progressiva valorização da democracia participativa, a perspectiva da participação consolidou-se tanto entre técnicos e estudiosos da gestão pública quanto entre formuladores e dirigentes dos programas de reforma do Estado que se tornaram típicos naquele período (p. 117).
}

Gestada na realidade social, a ideia de participação fortaleceu-se no campo da gestão pública, havendo a ação de movimentos em prol da participação popular nos processos governamentais e na implementação de políticas públicas. No entanto, é preciso ressaltar que a materialização da participação pode ocorrer consubstanciada em posicionamentos distintos para o encaminhamento das políticas públicas. Por um lado, pode ocorrer um procedimento que vise à elevação das comunidades organizadas à condição de sujeitos das operações governamentais e, por outro, pode ocorrer a transferência de responsabilidades e legitimação de ações governamentais em prol de uma suposta participação.

Conscientes de que as decisões e o encaminhamento de políticas públicas trazem, em seu âmago, os interesses da classe dirigente, defendemos que a participação é um processo por meio do qual a classe trabalhadora tem a oportunidade de contribuir na formação de planos coletivos, objetivando a intervenção na realidade social e histórica.

O processo participativo, portanto, é dinâmico e se constrói durante sua efetivação. Então, explicitar o que se entende por participação e como ela pode contribuir para o fortalecimento da gestão democrática na realidade local pode tornar-se uma contribuição genuína, principalmente na área educacional.

552 - RBPAE - v. 32, n. 2, p. 549 - 569 mai./ago. 2016 
A vontade de poder quantificar os graus de participação, aliada à inexistência de um critério consensual que a defina, leva o pesquisador a ter que lidar com duas questões que dificultam qualquer análise. Em primeiro lugar é muito complexo dar conta da consciência individual do ator chamado a participar, sua verdadeira e íntima vocação, compreendida aqui como a disposição pessoal para engajarse no processo. Outro problema é que esta situação permite associar o grau de participação ao número de pessoas consultadas; ou seja, induz a acreditar que muitos indivíduos, interferindo fortemente em muitas decisões, constitui (sic) um sistema bastante participativo. (CATANI; GUTIERREZ, 1998, p. 61).

Com isso, pretendemos dizer que a simples consulta aos indivíduos não garante uma participação consciente, podendo ocorrer uma decisão prejudicial ou equivocada, autorizada por um grande número de pessoas (Idem, 1998).

A prática da cidadania implica participação por meio do efetivo exercício da democracia; por isso, a participação na gestão do sistema e das instituições torna-se tão importante quanto necessária para uma política voltada à garantia do princípio constitucional da gestão democrática. Explicitar o que se entende por participação e como ela pode contribuir para o fortalecimento da gestão democrática é, portanto, ponto central. Todavia, é preciso tomar o devido cuidado para que o processo democrático não seja entendido como aquele capaz de subordinar a vontade da maioria à decisão de uma minoria interessada nos compromissos burgueses.

Nesse entendimento, um pequeno grupo fala pela maioria, estabelecendo a posição mais "adequada", desconsiderando a vontade e a necessidade do coletivo. Por isso, é preciso entender a participação como verdadeiro exercício democrático, sem reduzi-la a uma questão de método, no qual a população é levada a contribuir na tomada de decisões, mas de maneira a desconsiderar os valores e os interesses coletivos.

A participação tendenciosa e parcial se distancia de uma democracia, caracterizando-se mais como atividade ilusória, na qual os interesses coletivos são obscurecidos e desconsiderados, enfraquecendo o próprio desenvolvimento da sociedade. Nesse sentido, são esclarecedoras as palavras de José Nun, ao abordar o processo democrático na América do Sul:

Acontece que uma coisa é conceber a democracia como um método para a formulação e tomada de decisões no âmbito estatal; e outra bem distinta imaginá-la como uma forma de vida, como um modo cotidiano de relação entre homens e mulheres que orienta e que regula o conjunto das atividades de uma comunidade. Estou aludindo ao contraste entre uma democracia governada e uma democracia governante, isto é, genuína. (Nun apud BORON, 1994, p. 9). 
A esse respeito, compactuamos com o pensamento gramsciano quando o autor defende a necessidade de que o indivíduo seja capaz "de pensar, de estudar, de dirigir ou controlar quem dirige" (GRAMSCI, 2006, p. 49). Nessa perspectiva, participar consiste em colaborar de forma efetiva na construção de um plano de ação coletivo, observando que essa construção deve superar o conflito das partes e alcançar um consenso, mas não o consenso entendido como aceitação da concepção defendida pela classe dominante, o qual impossibilita totalmente a elaboração de um projeto contra-hegemônico, mas o consenso baseado no diálogo, onde a voz mais fraca, mesmo que oriunda de uma ínfima minoria, é ouvida e considerada.

A participação nos limites da sociedade capitalista é, portanto, um processo no qual a classe trabalhadora tem oportunidade de contribuir na formação de planos coletivos, objetivando a intervenção na realidade social e histórica. Assim, não se pode confundir o mero ativismo imediatista com participação, pois esta implica uma consciência radical sobre a necessidade de transformação das condições materiais da vida em sociedade, enquanto a outra expressa superficialidade de ações, contribuindo para o fortalecimento do pensamento hegemônico dominante.

\begin{abstract}
Se o povo produz e não usufrui dessa produção, ou se produz e usufrui mas não toma parte na gestão, não se pode afirmar que sua participação seja verdadeira e efetiva. Assim sendo, "a construção de uma sociedade participativa" torna-se utopia/força que dá sentido a todas as microparticipações sociais. (VERZA, 2000, p. 110.).
\end{abstract}

Embora o processo participativo pareça algo de fácil execução, sua efetivação no campo das políticas educacionais se torna algo bastante complexo, pois a organização social está pautada na relação de desiguais e, nesse sentido, a participação pode ser falseada, evidenciando interesses da classe dominante.

Sendo contraditório e difícil, o processo participativo se fundamenta no exercício do diálogo entre as partes, procurando alcançar um consenso. Enfim, o processo participativo é, em sua essência, um processo dialético de constituição de democracia e de cidadania, no qual, conforme pode ser observado nas reflexões feitas por Gramsci nos Cadernos do Cárcere, as classes excluídas podem deixar de ser dirigidas e tornarem-se dirigentes.

\footnotetext{
Intimamente associado à concepção de hegemonia, “dirigente” em Gramsci não tem o significado de chefe, vanguarda ou liderança que se sobrepõe e conduz os outros; nem de "diretor", "gerente", "executivo" ou de toda uma terminologia que hoje, com palavras diferentes preserva a relação fundamental de poder entre superior e inferior, comandante e comandado, dirigente e dirigido, com a conseqüente divisão da sociedade em classes. Uma sociedade que quer ser realmente democrática,
} 
afirma Gramsci, não visa apenas a que o operário manual se torne qualificado, mas que cada "cidadão" se torne "governante", obtendo da sociedade a aprendizagem gratuita da capacidade e da preparação técnica geral necessárias para tal fim, "sem a qual permanece 'especialista' e não se torna 'dirigente' (especialista + político)". (SEMERARO, 2003, p. 271.).

A prática do processo participativo essencialmente democrático eleva social e intelectualmente as camadas populares e as torna-as capazes de estabelecer o caráter da sociedade que melhor expressa seus interesses coletivos.

O poder não se concentra em algum pólo particular, de cima ou de baixo, de dentro ou de fora, mas é uma prática ético-política tensa e aberta entre diversos sujeitos e organizações que disputam projetos diferentes de sociedade. É uma relação dialética que se estabelece entre sociedade civil e sociedade política, que acaba se tornando uma "relação pedagógica", um reconhecimento de recíproca valorização, porque não há mais alguém ou algo que tenha prerrogativas definitivas: o que se tem em vista é, precisamente, a hegemonia da democracia, ou seja, a socialização do saber e do poder. (Ibidem).

No campo político-educacional, essa possibilidade de participação democrática, em que o dirigido tem a oportunidade de se tornar dirigente, dá-se a partir da existência de: Conselhos de Educação e Conselhos de Acompanhamento e Controle Social, os quais têm, de maneira geral, a função de acompanhar, discutir, avaliar e propor ações para os gestores públicos na busca de uma educação efetivamente de qualidade. Em que pese a discussão de qualidade no âmbito empresarial, aqui defendemos a perspectiva de uma educação pública de qualidade social.

Trata-se da formação de uma atitude e de uma prática democrática que permeiam a gestão educacional, não como um fim em si mesma, mas como estratégia para a concretização da qualidade social da educação, que inclui a formação de cidadãos democráticos. (BELLONI, 2003, p. 233).

É por isso que a prática democrática possibilita o surgimento de "novos dirigentes", entendidos de forma diferente daquela dada pela concepção liberal. Os participantes desse exercício de democracia tornam-se protagonistas de sua própria história e determinante na história coletiva.

De fato, diferentemente da significação que o termo recebe na cultura liberal, os "novos dirigentes", como se pode deduzir da visão de Gramsci, são considerados em sua singularidade, mas não coagulados em seu individualismo; são livres, mas não anárquicos e pulverizados; são organizados em torno de um projeto de democracia popular, não "socialmente entrosados" para auferir interesses corporativos; são formados e não apenas informados, transformadores e não apenas "eficientes"; 
anseiam pela arte e não por modismos, são populares e não populistas, solidários e não assistencialistas. (SEMERARO, 2003, p. 272, grifos do autor).

Por meio de um processo participativo, que expressa materialmente o exercício da democracia, é possível almejar práticas político-educacionais que sejam pensadas a partir da realidade dos sujeitos envolvidos. Para tanto, a gestão democrática torna-se componente fundamental para o desenvolvimento de uma consciência coletiva que não anule o pensamento individual, mas o transforme em prol dos interesses coletivos. Isso significa, em última análise, um exercício radical de democracia, rompendo com a verticalidade existente em termos de decisões políticas para o campo educacional.

Assim, a educação envolve todos os seus sujeitos, tornando-os iguais e possibilitando sua inserção no processo, não apenas de execução, mas de planejamento, de elaboração e, também, de fiscalização de ações, de projetos e de medidas implementadas no contexto educacional. Os indivíduos superam a passividade e assumem postura ativa na efetivação de propostas políticoeducacionais, tornando-se sujeitos e não meras peças da engrenagem comandada externamente.

\section{MARCOS LEGAIS SOBRE A GESTÃO DEMOCRÁTICA}

O principal marco legal que caracteriza a abertura política no Brasil é a Constituição Federal de 1988, que é explícita ao declarar que o país está assentado em um Estado Democrático de Direito, que tem entre seus fundamentos a cidadania. No entanto, conforme nos alerta Tonet (2007), no atual estágio do capitalismo, a cidadania é um "conceito da moda" e tornou-se "sinônimo de liberdade" (p. 1). Para esse autor, ser cidadão, na ótica liberal-burguesa, "é ser membro de uma comunidade jurídica e politicamente organizada, que tem como fiador o Estado e no interior da qual o indivíduo passa a ter determinados direitos e deveres" (Idem, p. 4). Essa forma de entendê-la traz em seu bojo muito mais limites do que possibilidades. Isso ocorre em razão de que a cidadania não é isenta dos conflitos de classe (mesmo que o ordenamento jurídico negue esse conflito, quando coloca a todos em um patamar de igualdade formal e não real) e, como tal, é contraditória.

O exercício da democracia e, consequentemente, da cidadania, em uma ordem regida pelo capital na qual o país está inserido, apresenta limites para o processo emancipatório, pois a emancipação é política e não humana, conforme 
defendido pelos socialistas ${ }^{2}$, visto que esta só será possível com a superação do capital.

Nos limites da sociedade capitalista e para o objetivo do presente estudo, podemos considerar que a cidadania possível em dado momento histórico é aquela que exerce determinados direitos e deles usufrui. Para o campo específico da gestão democrática no setor público, a cidadania precisa ser exercida a partir da participação dos indivíduos em atos e ações que possam colaborar para o avanço do entendimento das necessidades coletivas.

A esse respeito, é importante lembrar a cláusula pétrea da Constituição Federal que estabelece, no parágrafo único de seu Art. $1^{\circ}$, que "todo o poder emana do povo, que o exerce por meio de representantes eleitos ou diretamente" (BRASIL, 1988, p. 3). Isso quer dizer que a democracia brasileira se assenta tanto em uma democracia direta ou participativa quanto na democracia indireta e representativa. Entretanto, a democracia indireta ou representativa tem-se mostrado como aquela possível de ser executada, em razão da impossibilidade de envolver todos os sujeitos em um amplo processo participativo. Por isso, cabe um esclarecimento a respeito da democracia representativa, pois, dependendo da forma como a representação foi construída, não se caracteriza como representante do coletivo. É importante destacar que a pessoa que representa precisa pautar sua participação nos interesses dos representados e isso só se efetiva se houver discussão a partir da base. Caso contrário, a participação não é representativa e se caracteriza como participação apenas formal, sem efetividade no campo da representação e contrária às indicações constitucionais de dar poder ao povo.

Nesse aspecto, a participação popular se caracteriza como fundamental para a democracia e, consequentemente, para o exercício da cidadania. Ações que contrariam o princípio constitucional de democracia demonstram-se autoritárias e fragilizadas. Assim, a cidadania é exercida por meio da participação (direta ou indireta) nos atos e nas ações públicas. A participação, então, dá-se pelo acompanhamento dos atos dos gestores públicos, que se faz na ampla discussão sobre suas intenções e ações para a efetivação de políticas públicas sociais.

Nesse contexto, a administração pública direta e indireta deve reger seus atos por meio dos princípios de legalidade, de impessoalidade, de moralidade, de publicidade e de eficiência, conforme art. 37 do texto constitucional. Ainda, o $\int$

2 A emancipação política é parcial pois cumpre a função democrática defendida pela burguesia, na qual os indivíduos exercem seus direitos nos limites do capitalismo, ou seja, em uma sociedade que se sustenta na lógica da exploração, enquanto que a emancipação humana é o objetivo perseguido pelos socialistas. que buscam a superação do capital e, portanto, uma sociedade efetivamente pautada na igualdade do gênero humano. Karl Marx faz reflexões significativas sobre a questão em dois textos originais: Sobre a Questão Judaica, de 1843, e Glosas Críticas Marginais ao Artigo "O Rei da Prússia e a Reforma Social" de um Prussiano, de 1844. 
$3^{\circ}$ do mesmo artigo preceitua que a lei disciplinará as formas de participação do usuário na administração pública direta e indireta (BRASIL, 1988).

No tocante à educação, a Constituição Federal é incontroversa ao incluir em seus princípios a "gestão democrática do ensino público" (Idem, art. 206, VII). Esses dispositivos constitucionais criaram a possibilidade de institucionalização da participação em escolas e sistemas educacionais. Tanto que a Lei 9394/96, de Diretrizes e Bases da Educação Nacional também disciplina a questão quando prevê:

Art. $3^{\circ} \mathrm{O}$ ensino será ministrado com base nos seguintes princípios: [...]VIII - gestão democrática do ensino público, na forma desta Lei e da legislação dos sistemas de ensino [...]. Art. 14 Os sistemas de ensino definirão as normas da gestão democrática do ensino público na educação básica, de acordo com as suas peculiaridades e conforme os seguintes princípios: [...] I - participação dos profissionais da educação na elaboração do projeto pedagógico da escola; [...] II - participação das comunidades escolar e local em conselhos escolares ou equivalentes. (BRASIL, 1996, pp. 27833 e 27835).

A Lei 9394/96 delegou aos sistemas de ensino a definição de normas de gestão democrática, indicando que os princípios previstos nos incisos I e II do artigo 14 sejam considerados. Nesse aspecto, os sistemas de ensino (federal, estadual e municipal) precisam estar atentos a um direcionamento que, efetivamente, assegure a gestão democrática.

Da mesma forma, o Plano Nacional de Educação, Lei 13005/14, leva a gestão democrática como pressuposto para a efetivação de melhoria da gestão pública, quando prevê, na estratégia 19.2, a necessidade de ampliação dos programas de apoio e formação de conselheiros (Conselhos de Acompanhamento e Controle Social do FUNDEB, Conselhos de Alimentação Escolar, Conselhos Regionais e outros); na estratégia 19.3, o incentivo à constituição de fóruns permanentes de educação; e, na estratégia 19.5, o fortalecimento de conselhos escolares e conselhos municipais de educação, como instrumentos de participação e fiscalização na gestão escolar e educacional, inclusive por meio de programas de formação de conselheiros, assegurando-se condições de funcionamento autônomo; dentre outras previsões (BRASIL, 2014).

Os pressupostos legais indicam que a participação social e popular se constitui em pilar basilar para a democracia, exercício da cidadania e controle e acompanhamento das políticas educacionais. Em que pesem os limites da organização social pautada na divisão de classes, a participação social e popular tem como característica básica a horizontalidade nas relações colegiadas, de forma a superar o possível autoritarismo, clientelismo e mandonismo na condução das políticas públicas. 
A partir da previsão constitucional e da legislação infraconstitucional caracterizada pelas Leis 9394/96 e 13005/14, os sistemas de ensino assumem a responsabilidade de normatizar e efetivar a gestão democrática, de modo que esta possa avançar da simples previsão para a realidade material. Esse é um passo bastante importante para dar autonomia aos Sistemas de ensino, instituições escolares e cidadãos. Somente o exercício prático da democracia (direta ou indireta) eleva os sujeitos a detentores das decisões e responsáveis pelos caminhos escolhidos para a efetivação dos direitos legalmente previstos. Quando esse processo ocorre de maneira equivocada, as decisões podem levar a um caminho tortuoso para todos. É o que pretendemos mostrar no caso do Sistema Municipal de Ensino analisado.

\section{A GESTÃO DEMOCRÁTICA NO SISTEMA MUNICIPAL DE ENSINO: ENTRE A PREVISÃO E A REALIDADE}

Ponta Grossa, município localizado no centro-sul paranaense, em região denominada Campos Gerais, de forte influência patriarcal e oligárquica, que se reflete na organização política municipal, esteve, historicamente, distanciada dos interesses e das necessidades da classe trabalhadora, principalmente dos fragmentos de classe com menores condições de sobrevivência. Essa característica influencia sobremaneira o entendimento da participação em todos os setores da sociedade, pois a participação e o controle social no acompanhamento das políticas públicas são fragilizados devido à compreensão de que apenas alguns têm condições de tomar decisões que impactam a coletividade. As possibilidades de exercício da gestão democrática no âmbito do sistema municipal de ensino não são isentas de tais influências. Demonstrar como isso se evidencia é a pretensão da presente exposição.

No município analisado, a institucionalização da participação ocorreu muito antes da criação do Sistema Municipal de Ensino, quando o Conselho Municipal de Educação foi criado por meio da Lei Municipal no 5172, de 24 de novembro de 1995. O Sistema Municipal de Ensino foi organizado apenas no ano de 2002, pela Lei Municipal no 7081/02. É preciso ressaltar que, quando os municípios institucionalizam seu próprio sistema de ensino se autodeclaram aptos à autonomia, estando cientes de que criarão normas complementares para seu sistema, responsabilizando-se pela autorização, pelo credenciamento e pela supervisão de suas instituições de educação e das instituições privadas de Educação Infantil, conforme previsto no artigo 11 da Lei no 9394/96. Dessa forma, a institucionalização do sistema municipal de ensino traz em seu bojo a necessidade de organização interna e externa pautada nos princípios da gestão 
democrática, visto que deverá ter também, além de condições estruturais, organizacionais e recursos humanos para o atendimento das demandas, um órgão normativo que se responsabilize normativamente pelo funcionamento efetivo da organização educacional municipal, não apenas no setor público, mas também no setor privado, conforme estabelecido na legislação pertinente.

Assim, com a criação do Sistema Municipal de Ensino, O conselho municipal de educação, como órgão normativo do sistema, precisa exercer as funções específicas que lhe dão a capacidade jurídica, política e social para instituir normas, fiscalizar e acompanhar a implementação de políticas para o setor educacional no respectivo município, ou seja, se constitui como possibilidade de exercício democrático, que se efetivará ou não, conforme ocorrer a representatividade e o efetivo envolvimento de seus membros nesse espaço.

Desde sua criação em 1995, ao Conselho Municipal de Educação de Ponta Grossa foram delegadas diversas funções, conforme podemos observar no quadro 1 a seguir:

\section{Quadro 1 - Funções do Conselho Municipal de Educação - Ponta Grossa $-1995-2011$}

\begin{tabular}{|c|c|c|c|c|c|c|}
\hline \multirow{2}{*}{ Leis Municipais } & \multicolumn{6}{|c|}{ Funções Previstas } \\
\cline { 2 - 7 } & Normativa & Consultiva & Deliberativa & Propositiva & Mobilizadora & Fiscalizadora \\
\hline Lei Municipal $n^{0} 5172 / 95$ & $\mathrm{X}$ & $\mathrm{X}$ & - & - & - & - \\
\hline Lei Municipal $\mathrm{n}^{0} 6917 / 02$ & $\mathrm{X}$ & $\mathrm{X}$ & - & - & - & - \\
\hline Lei Municipal 7423/03 & $\mathrm{X}$ & $\mathrm{X}$ & $\mathrm{X}$ & $\mathrm{X}$ & $\mathrm{X}$ & $\mathrm{X}$ \\
\hline Lei Municipal $\mathrm{n}^{0} 10593 / 11$ & $\mathrm{X}$ & $\mathrm{X}$ & $\mathrm{X}$ & $\mathrm{X}$ & $\mathrm{X}$ & $\mathrm{X}$ \\
\hline
\end{tabular}

Fonte: Elaboração das autoras, com base nas Leis Municipais citadas.

As diversas funções exercidas por esse órgão colegiado são assim entendidas pela legislação municipal: (1) função normativa: quando fixar doutrinas e normas gerais (Leis no 5172/95, 6917/02, 7423/03 e 10593/11); (2) função consultiva: quando responder às consultas e apreciar recursos em matéria de educação geral (Leis no5172/95, 6917/02, 7423/03 e 10593/11); (3) função deliberativa: quando decidir sobre questões e matérias trazidas a seu conhecimento relacionadas à Educação no âmbito do Conselho (Leis n ${ }^{\circ}$ 7423/03 e 10593/11); (4) função propositiva: quando contribuir, emitindo opinião ou oferecendo sugestões, na discussão e/ou definição das políticas e do planejamento educacional (Leis n $7423 / 03$ e 10593/11); (5) função mobilizadora: quando visar a esforços para manter a sociedade informada e atuante em relação às questões educacionais do município (Leis n $n^{\circ} 7423 / 03$ e 10593/11); função fiscalizadora: 
quando acompanhar o desenvolvimento de ações e do cumprimento da legislação e das normas educacionais, pelo Poder Executivo, instituições e estabelecimentos de ensino vinculados ao Sistema Municipal (Leis no 7423/03 e 10593/11).

As funções previstas indicam possibilidades de exercício da democracia, pois fortalecem o processo decisório de um colegiado representativo da sociedade. Nesse sentido, entendemos que o exercício dessas funções deve (ou deveria) promover a participação de diferentes segmentos na discussão e nos encaminhamentos de propostas político-educacionais para a educação municipal e, dessa forma, contribuir para o avanço qualitativo da educação oferecida à população. Em que pese a Composição do Conselho Municipal de Educação do município analisado apontar para ampla participação ${ }^{3}$, a prática do colegiado pode ser viciada, tanto pelo desvio quanto pela omissão dos interesses dos representados e da comunidade em geral, causando sério impacto na realidade educacional e social ${ }^{4}$.

Desde a criação do Sistema Municipal de Educação, em 2002, e a alteração das funções do Conselho Municipal de Educação, em 2003, quando este passou a exercer efetivamente a função deliberativa, até 2015, esse Colegiado elaborou 27 deliberações. No entanto, a pesquisa sobre os principais assuntos tratados no Conselho Municipal de Educação indicou que 41\% deles trataram sobre a organização de Calendário de Reuniões e cronograma de atividades, conforme demonstrado na Tabela 1 a seguir.

3 Atualmente, segundo o artigo $6^{\circ}$ da Lei Municipal n ${ }^{\circ}$ 10593/11, o Conselho Municipal de Ponta Grossa é composto por 21 representantes: quatro da Secretaria Municipal de Educação; um do Núcleo Regional de Educação-PG; dois da Universidade Estadual de Ponta Grossa (UEPG) - Departamento de Educação e Departamento de Métodos e Técnicas; um da Universidade Tecnológica Federal do Paraná - Ponta Grossa (UTFPR/PG); um dos estabelecimentos de ensino superior particulares da cidade de Ponta Grossa; um da Federação da Indústria do Estado do Paraná (FIEP), da Coordenação de Ponta Grossa; um representante da Rede Particular de Ensino Fundamental (anos iniciais) de Ponta Grossa; um da Rede Particular de Educação Infantil de Ponta Grossa; um do Sindicato dos Servidores Públicos Municipais de Ponta Grossa; um do Conselho Municipal dos Direitos da Criança e do Adolescente de Ponta Grossa(CMDCA/PG); um da Promotoria da infância e da juventude (Conselho Tutelar) de Ponta Grossa; um dos diretores das escolas municipais ou centros municipais de Educação Infantil; um da União das Associações de Moradores de Ponta Grossa (UAMPG); um dos professores do Quadro Próprio do Magistério Estadual, no exercício da atividade docente, em estabelecimento de ensino estadual de Ponta Grossa; um de pais de alunos matriculados na Rede Municipal de Ensino; um das escolas e/ou centros de Educação Especial de Ponta Grossa; um do Conselho Municipal dos Direitos das Pessoas Portadoras de Deficiências (CMDPD).

4 Essa questão será abordada no presente texto, ao se apresentarem as deliberações e atuação do órgão colegiado em relação ao PL n ${ }^{\circ}$ 202/2015. 
Tabela 1 - Número de deliberações do Conselho Municipal de Educação

- Ponta Grossa - 2004 - 2015

\begin{tabular}{|c|c|c|c|}
\hline \multirow{2}{*}{ Ano } & \multicolumn{2}{|c|}{$\mathbf{N}^{0}$ de deliberações conforme assuntos tratados } & \multirow{2}{*}{ Total } \\
\cline { 2 - 4 } & Calendário de reuniões & $\begin{array}{c}\text { Normas para o Sistema } \\
\text { de Ensino }\end{array}$ & 6 \\
\hline 2004 & 2 & 4 & 2 \\
\hline 2005 & 1 & 1 & 2 \\
\hline 2006 & - & 2 & 1 \\
\hline 2007 & - & 1 & - \\
\hline 2008 & - & - & 1 \\
\hline 2009 & 1 & - & 1 \\
\hline 2010 & 1 & - & 3 \\
\hline 2011 & 3 & - & 5 \\
\hline 2012 & 1 & 4 & 3 \\
\hline 2013 & 1 & 2 & 2 \\
\hline 2014 & 1 & 1 & 1 \\
\hline 2015 & - & 1 & 27 \\
\hline Total geral & 11 & 16 & 2 \\
\hline
\end{tabular}

Fonte: Elaboração das autoras, com base nas informações coletadas no Portal da Secretaria Municipal de Educação/Conselho Municipal de Educação de Ponta Grossa. ${ }^{5}$

Observamos, ainda, que, em anos de final de gestão municipal (ano eleitoral - 2004 e $2012^{6}$ ), houve maior número de deliberações normativas, indicando preocupação em normatizar questões específicas do Sistema Municipal de Educação, conforme pode ser observado nos anos de 2004 e 2012.

Em relação aos assuntos tratados nesses dois anos de final de gestão municipal, percebemos que houve, no ano de 2004, a necessidade de se normatizarem questões organizativas do Sistema Municipal de Educação, criado em 2002. Convém ressaltar que também a criação do Sistema Municipal de Educação esteve inserida na discussão sobre a oferta dos anos iniciais do Ensino Fundamental, pois, no ano de 2001, a Secretaria Municipal de Educação reorganizou a oferta dessa etapa, matriculando alunos com seis anos incompletos. O Conselho Estadual de Educação emitiu, naquela oportunidade, parecer contrário à respectiva oferta, impulsionando o município à criação de sistema

5 Disponível em: http://sme.pontagrossa.pr.gov.br/conselho.php >. Acesso em: 20 nov. 2015.

6 De 2001 a 2004, o município foi governado por Péricles de Holleben Melo, do PT, e, no período entre 2005 e 2012, por Pedro Wosgrau Filho, do PSDB. 
próprio, visando a legitimar as ações empreendidas ${ }^{7}$. Assim, as deliberações elaboradas no ano de 2004 visaram, de forma geral, a organizar o Sistema Municipal, recém-criado, oferecendo normas específicas para seu funcionamento, conforme podemos observar no Quadro 2.

\section{Quadro 2 - Principais assuntos deliberados no Conselho Municipal de} Educação de Ponta Grossa em 2004.

\begin{tabular}{|c|c|c|}
\hline Deliberação & Assunto Indicado & Objetivo \\
\hline $01 / 2004$ & $\begin{array}{c}\text { Normas e procedimentos para } \\
\text { processos de autorização, } \\
\text { prorrogação, verificação e cessação } \\
\text { dos estabelecimentos de ensino } \\
\text { que compreendem o Sistema } \\
\text { Municipal de Ensino. }\end{array}$ & $\begin{array}{c}\text { Organizar Comissões de trabalho } \\
\text { no Conselho Municipal de } \\
\text { Educação. }\end{array}$ \\
\hline $02 / 2004$ & $\begin{array}{c}\text { Normas para a Educação Infantil } \\
\text { no Sistema Municipal de Ensino de } \\
\text { Ponta Grossa. }\end{array}$ & $\begin{array}{c}\text { Normatizar a oferta da Educação } \\
\text { Infantil em Instituições Públicas e } \\
\text { Privadas. }\end{array}$ \\
\hline $03 / 2004$ & $\begin{array}{c}\text { Normas para criação, autorização } \\
\text { para funcionamento, verificação e } \\
\text { cessação de atividades escolares } \\
\text { e projetos pedagógicos do Sistema } \\
\text { Municipal de Ensino de Ponta } \\
\text { Grossa. }\end{array}$ & $\begin{array}{c}\text { Subsidiar o Sistema Municipal } \\
\text { nos Procedimentos especificos de } \\
\text { criação, autorização e verificação } \\
\text { de instituições escolares. }\end{array}$ \\
\hline $04 / 2004$ & $\begin{array}{c}\text { Normas para autorização de } \\
\text { funcionamento da Primeira Etapa } \\
\text { do Ensino Fundamental Ciclado no } \\
\text { municipio de Ponta Grossa. }\end{array}$ & $\begin{array}{c}\text { Oferecer amparo legal para a } \\
\text { oferta dos anos iniciais do Ensino } \\
\text { Fundamental e matrícula de } \\
\text { crianças com seis anos a completar } \\
\text { em 31 de dezembro. }\end{array}$ \\
\hline
\end{tabular}

Fonte: Elaboração das autoras, com base nas deliberações 01/2004, 02/2004, 03/2004 e 04/2004 do Conselho Municipal de Educação de Ponta Grossa ${ }^{8}$.

Em contrapartida, no ano de 2012, outras questões estavam em pauta nas discussões do Conselho Municipal de Educação, conforme mostra o Quadro 3.

\footnotetext{
$7 \quad$ Para melhor entender essa questão, indicamos a leitura de Flach, 2015.

8 Disponível em: http://sme.pontagrossa.pr.gv.br/conselho.php>. Acesso em: 20 nov. 2015.
} 


\section{Quadro 3 - Principais assuntos deliberados no Conselho Municipal de Educação - Ponta Grossa - 2012}

\begin{tabular}{|c|c|c|}
\hline Deliberação & Assunto Indicado & Objetivo \\
\hline $01 / 2012$ & $\begin{array}{c}\text { Normas para inscrições de } \\
\text { entidades beneficentes que } \\
\text { possuam atividade preponderante, } \\
\text { na área educacional, circunscritas } \\
\text { no âmbito da competência do } \\
\text { Sistema Municipal de Ensino. }\end{array}$ & $\begin{array}{c}\text { Certificar entidades beneficentes à } \\
\text { Legislação Federal para usufruto } \\
\text { de benefícios legais (isenção fiscal, } \\
\text { recebimento de recursos públicos, } \\
\text { etc). }\end{array}$ \\
\hline $02 / 2012$ & $\begin{array}{c}\text { Normas para matrícula } \\
\text { transferência, classificação, } \\
\text { reclassificação e regularização de } \\
\text { vida escolar em estabelecimentos } \\
\text { que ofertem Anos Iniciais do Ensino } \\
\text { Fundamental (10 ao 50 ano), nas } \\
\text { suas diferentes modalidades. }\end{array}$ & $\begin{array}{c}\text { Normatizar o processo de } \\
\text { matrículas regulares, o ingresso } \\
\text { de alunos oriundos de sistemas de } \\
\text { ensino do exterior, de alunos que } \\
\text { nunca frequentaram uma instituição } \\
\text { formal de ensino, bem como aos } \\
\text { que apresentam condiçães de } \\
\text { avançarem nos seus estudos. }\end{array}$ \\
\hline $03 / 2012$ & $\begin{array}{c}\text { Normas para a Educação Infantil } \\
\text { no Sistema Municipal de Ensino de } \\
\text { Ponta Grossa. }\end{array}$ & $\begin{array}{c}\text { Adequar normas já existentes à } \\
\text { legislação atual. }\end{array}$ \\
\hline $05 / 2012$ & $\begin{array}{c}\text { Normas para a Educação de Jovens } \\
\text { e Adultos no Ensino Fundamental } \\
\text { do Sistema Municipal de Ensino de } \\
\text { Ponta Grossa. }\end{array}$ & $\begin{array}{c}\text { Regulamentar a oferta da } \\
\text { modalidade de Educação de Jovens } \\
\text { e Adultos na Rede Municipal de } \\
\text { Ensino. }\end{array}$ \\
\hline
\end{tabular}

Fonte: Elaborado pelas autoras com base nas deliberações 01, 02, 03 e 05/2012 do Conselho Municipal de Educação de Ponta Grossa9.

O que pode ser observado nos anos analisados é que o Conselho Municipal de Educação, que deveria ser a instância de exercício de gestão democrática na qual as funções previstas indicariam possibilidades de discussão e efetivo exercício democrático, não exerceu efetivamente as funções a ele legalmente impostas, caracterizando-se muito mais como órgão normatizador para as demandas específicas da Secretaria Municipal de Educação. Essa forma de funcionamento do Conselho Municipal de Educação indica falta de vinculação de seu funcionamento com demandas sociais mais amplas. Nessa perspectiva, oferecem-nos importante reflexão as palavras de Oliveira et al. (2006), que expressam preocupação com o funcionamento de Conselhos Municipais de Educação na região de Campinas: "ao estudarmos a questão dos colegiados nos municípios não podemos esquecer de fenômenos, que apesar do tempo, podem ainda estar presentes e dificultar o funcionamento dos mesmos: tratando-se do clientelismo e do mandonismo" (p. 13).

9 Disponível em: <http://sme.pontagrossa.pr.gov.br/conselho.php>. Acesso em: 22/11/2015 
Em que pesem as questões apontadas pelos autores, é importante destacar que a democratização da educação e da gestão educacional precisa passar, necessariamente, pelo envolvimento da comunidade. E, nesse sentido, o Conselho Municipal de Educação pode indicar para a democratização do poder local e, consequentemente, para o efetivo exercício da democracia (nos limites possíveis da atual forma de sociabilidade).

As deliberações emitidas pelo CME apontam para um funcionamento atrelado às demandas solicitadas pela Secretaria Municipal de Educação, sem envolvimento mais efetivo de seus membros na política educacional do município, deixando inertes as funções propositiva, mobilizadora e fiscalizadora.

Essa questão mostrou-se evidente quando, no ano de 2015, o executivo municipal propôs, em projeto de Lei específico (PL 202/15), alteração no Plano de Cargos e Salários dos Professores vinculados à Rede Municipal de Ensino, ignorando atribuição dada ao CME, conforme inciso XI do art. $5^{\circ}$ da Lei Municipal n ${ }^{\circ}$ 10593/11, de "acompanhar o cumprimento da Legislação sobre a carreira dos profissionais da educação, manifestando-se quando necessário”. Em julho de 2015, a Prefeitura de Ponta Grossa encaminhou ao legislativo municipal projeto de lei para alteração da carreira docente no município. A elaboração da proposta, que culminou com o PL 202/2015, teve como interlocutores apenas pessoas indicadas pelo Poder Público Municipal e Sindicato dos Servidores Públicos Municipais ${ }^{10}$, sem oferecer ampla discussão a outros setores como o Conselho Municipal de Educação, Instituições Formadoras de Professores e demais interessados. Ao chegar ao legislativo municipal, houve intensa reivindicação social para um debate público a respeito da carreira docente, visto que o PL previa a contratação de profissionais sem formação em Ensino Superior e equiparação salarial dos profissionais com esse nível de ensino com o salário de nível médio, ocorrendo uma redução salarial para os profissionais mais qualificados.

Ao ser chamado para o debate, o Conselho Municipal de Educação omitiu-se, admitindo não ter conhecimento da elaboração do Projeto de Lei, pois não havia participado ou promovido discussão a respeito da questão. Esse posicionamento do Conselho Municipal de Educação colaborou para uma aprovação intempestiva da proposta na Câmara de Vereadores.

Consideramos que a forma como a Prefeitura de Ponta Grossa, por meio da Secretaria Municipal de Educação, conduziu a elaboração e a aprovação do Projeto de Lei 202/15, que propôs a alteração na Carreira Docente, é, no mínimo,

10 Convém informar que o Sindicato dos Servidores Públicos Municipais negou-se a participar de uma discussão ampla a respeito do Projeto de Lei em pauta. A esse respeito, mais uma vez, esclarecem-nos as palavras de Antonio Gramsci, quando afirma que "qualquer indivíduo que prescinda de uma vontade coletiva e não procure criá-la, suscitá-la, ampliá-la, reforçá-la, organizá-la, é simplesmente um pretensioso, um 'profeta desarmado', um fogo-fátuo" (GRAMSCI, 2007, p. 289-299, grifo do autor). 
uma afronta a todos os dispositivos legais que devem orientar as políticas públicas, representando uma distorção do processo democrático. Nessa questão específica, os poderes executivo e legislativo evidenciaram como os "acordos políticos" são mais fortes do que o bem da população como um todo.

Esse fato corrobora que as ações do poder público responsável pelo Sistema Municipal de Ensino, legitimadas pelo Conselho Municipal de Educação, podem colaborar para retrocessos em relação às conquistas alcançadas ao longo do processo de reivindicação de participação popular nas decisões políticas. Nesse caso específico, entendemos que o retrocesso não foi apenas para a Educação, mas para todo o processo democrático, conquistado a duras penas pelos cidadãos brasileiros.

O contexto local tem explicitado, desde a criação do Sistema Municipal de Ensino, como a gestão democrática pode sofrer distorções no contexto da prática política. Entender e explicar tais distorções constitui-se em desafio para os pesquisadores da área.

\section{CONSIDERAÇÕES FINAIS}

As análises empreendidas até o presente momento são provisórias, mas indicam o quão difícil é efetivar a gestão democrática na realidade concreta. Embora os pressupostos legais estejam explícitos e amplamente discutidos na academia, sua efetivação está marcada por vinculações políticas e culturais, seus entraves se evidenciam fortemente na condução da discussão de temáticas afetas ao setor educacional.

O sistema municipal de ensino analisado vem evidenciando, ao longo de sua existência, que a participação popular na gestão pública ainda é uma realidade almejada, pois essa participação é tutelada por interesses governamentais e legitima ações dos gestores públicos, sem, necessariamente, promover um amplo debate a partir da base representada pelos indivíduos que compõem órgãos colegiados representativos.

Nessa perspectiva, a gestão democrática no âmbito do Sistema Municipal de Ensino de Ponta Grossa precisa constituir-se em meta a ser efetivada, visto que é prevista, mas não encontra guarida em órgão colegiado. Face aos argumentos apresentados no presente texto, pode-se afirmar que a representatividade na realidade analisada é deficitária e, consequentemente, o debate democrático também o é. Essas questões indicam entraves que precisam ser superados para que a gestão democrática deixe de ser apenas previsão legal para tornar-se real. 


\section{REFERÊNCIAS}

BELLONI, I. Educação. In: BITTAR, J. (Org.). Governos estaduais: desafios e avanços: reflexões e relatos de experiências petistas. São Paulo: Fundação Perseu Abramo, 2003. p. 230-246.

BORON, A. A. Estado, capitalismo e democracia na América Latina. Rio de Janeiro: Paz e Terra, 1994.

BRASIL. Lei No 13.005, de 25 de junho de 2014. Diário Oficial [da] República Federativa do Brasil, Poder Legislativo, Brasília, DF, 26 jun. 2014. Seção 1, n. 120-A, p. 1-7, edição extra, 2014.

. Lei No 9.394, de 20 de dezembro de 1996. Diário Oficial [da] República

Federativa do Brasil, Poder Legislativo, Brasília, DF, 23 dez. Seção 1, n. 248 p. 27833-27841. 1996

- Constituição da República Federativa do Brasil. Brasília. DF: SenadoFederal, 1988.

CATANI, A. M.; GUTIERREZ, G. L. Participação e gestão escolar: conceitos e potencialidade. In: FERREIRA: N. S. C. (Org.). Gestão democrática da educação: atuais tendências, novos desafios. São Paulo: Cortez, 1998. p. 59-75.

FLACH, S. F. Direito à educação e ampliação da escolaridade obrigatória em Ponta Grossa (2001 - 2008). 2011. 316 f. Tese (Doutorado em Educação) - Universidade Federal de São Carlos, São Carlos-SP, 2011. Disponível em: < http://www.bdtd.ufscar.br/htdocs/tedeSimplificado/tde_busca/arquivo. php?codArquivo=4037 >. Acesso em: 5 dez. 2015.

GRAMSCI, A. Cadernos do Cárcere. 4. ed. Rio de Janeiro: Civilização Brasileira, 2007. v. 3

. Cadernos do Cárcere. 4. ed. Rio de Janeiro: Civilização Brasileira, 2006. v. 2.

KOSIK, K. Dialética do Concreto. 2. ed. Rio de Janeiro: Paz e Terra, 1976. 
NOGUEIRA, M. A. Um Estado para a sociedade civil: temas éticos e políticos da gestão democrática. 2. ed. São Paulo: Cortez, 2005.

OLIVEIRA, C. et al. Conselhos Municipais de Educação: um estudo na região metropolitana de Campinas. Campinas: Alínea, 2006.

PONTA GROSSA. Projeto de Lei Municipal PL n⿳ 202/2015. Dispõe sobre o plano de empregos, carreira e remuneração do Magistério Público Municipal de Ponta Grossa, e dá outras providências. Disponível em: < http://www.cmpg. pr.gov.br/\# >. Acesso em: 05 mai.2015

. Lei Municipal $\mathbf{n}^{\mathbf{0}} \mathbf{1 0 5 9 3}$, de 20 de junho de 2011. Dispõe sobre o Conselho Municipal de Educação. Disponível em: < https://leismunicipais.com. br/a1/pr/p/ponta-grossa/lei-ordinaria/2002/691/6917/lei-ordinaria-n-69172002-altera-a-redacao-do-paragrafo-unico-do-art-1-da-lei-n-5172-de-11-04-95que-criou-o-conselho-municipal-de-educacao-cme >. Acesso em: 20 out. 2015.

. Lei Municipal $\mathbf{n}^{\mathbf{0}} \mathbf{7 4 2 3}$, de 17 de dezembro de 2003. Promove alterações no Conselho Municipal de Educação - CME. Disponível em: < https:// leismunicipais.com.br/a1/pr/p/ponta-grossa/lei-ordinaria/2003/742/7423/leiordinaria-n-7423-2003-promove-alteracoes-no-conselho-municipal-de-educacao >. Acesso em: 20 out. 2015.

Lei Municipal $\mathbf{n}^{\mathbf{0}} \mathbf{6 9 1 7}$, de 25 de maio de 2002. Altera a redação do parágrafo único do art. $1^{\circ}$ da lei $n^{\circ} 5172$, de 11/04/95, que criou o Conselho Municipal de Educação (CME). Disponível em: < https://leismunicipais.com. $\mathrm{br} / \mathrm{a} 1 / \mathrm{pr} / \mathrm{p} /$ ponta-grossa/lei-ordinaria/2002/691/6917/lei-ordinaria-n-69172002-altera-a-redacao-do-paragrafo-unico-do-art-1-da-lei-n-5172-de-11-04-95que-criou-o-conselho-municipal-de-educacao-cme >. Acesso em: 20 out. 2015.

Lei Municipal no 5172, de 24 de novembro de 1995. Cria o Conselho Municipal de Educação (CME) e dá outras providências. Disponível em: < https:/ / leismunicipais.com.br/a1/pr/p/ponta-grossa/lei-ordinaria/1995/518/5172/leiordinaria-n-5172-1995-cria-o-conselho-municipal-de-educacao-cme-e-da-outrasprovidencias?q=5172 > . Acesso em: 20 out. 2015 .

SEMERARO, G. Tornar-se "dirigente": o projeto de Gramsci no mundo globalizado. In: COUTINHO, C. N.; TEIXEIRA, A. P. Ler Gramsci, entender a realidade. Rio de Janeiro: Civilização Brasileira, 2003, p. 261-273. 
TONET, I. Cidadão ou homem livre. 2007. Disponível em: < http://ivotonet. xpg.uol.com.br/arquivos/cidadao_ou_homem_livre.pdf $>$. Acesso em: 26 out. 2015.

VERZA, S. B. As políticas públicas de educação no Município. Ijuí: UNIJUÍ, 2000.

SIMONE DE FÁTIMA FLACH é Doutora em Educação pela Universidade Federal de São Carlos (UFSCar). Docente do Departamento de Educação e do Programa de Pós-Graduação em Educação da Universidade Estadual de Ponta Grossa (UEPG). Co-editora da Revista Práxis Educativa - UEPG. Vice-coordenadora da Anpae - Paraná. E-mail: eflach@uol.com.br

KELLY LETíCIA DA SILVA SAKATA é Graduanda do curso de Licenciatura em Pedagogia da Universidade Estadual de Ponta Grossa (UEPG). Bolsista de Iniciação Científica - Fundação Araucária. E-mail: kelly.l.sakata@hotmail.com

Recebido em abril de 2016

Aprovado em junho de 2016 